\title{
CARACTERÍSTICAS INMUNOLÓGICAS DE LAS CÉLULAS EPITELIALES LIMBALES: ANÁLISIS IN VITRO DE LA FUNCIÓN DEL TLR4
}

\author{
IMMUNOLOGICAL CHARACTERISTICS OF LIMBAL \\ EPITHELIAL CELLS: IN VITRO ANALYSIS OF TLR4 FUNCTION
}

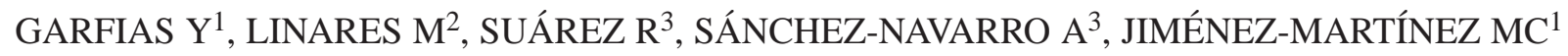

\begin{abstract}
RESUMEN
Objetivo: El objetivo del presente estudio fue determinar la expresión del TLR4 en el epitelio limbo esclero-corneal cultivado in vitro y determinar su función celular después de un estímulo con lipopolisacárido.

Métodos: Las células epiteliales limbales fueron obtenidas a partir de rodetes esclero-corneales y se expandieron; las células fueron estimuladas con diferentes dosis de lipopolisacárido de E. Coli y Pseudomonas durante 24 h. Después de la estimulación las células fueron cosechadas e identificadas con anticuerpos contra TLR4 humano y analizadas por citometría de flujo; el mRNA total se obtuvo y se realizó RT-PCR para la identificación de TLR4. La secreción de TNF-alfa fue evaluada por ELISA en el sobrenadante.

Resultados: Las células epiteliales limbales expandidas in vitro expresaron constitutivamente la molécula TLR4. Posterior a la estimulación con LPS, la expresión de TLR4 extracelular se aumentó tomando en cuenta la intensidad media de fluorescencia. Cuando se evaluó la expresión de mRNA de TLR4,
\end{abstract}

\begin{abstract}
Objective: The aim of the present study was to determine the expression of TLR4 on human limbal epithelial cells cultivated in vitro, and to determine its cellular function after stimulation with lipopolysaccharide (LPS).

Methods: Limbal epithelial cells were isolated from sclera-corneal rims and stimulated for 24 hours with different doses of LPS from $E$. coli and from Pseudomonas. After stimulation, the cells were harvested, stained with antibodies against human TLR4 and analysed by flow cytometry. mRNA was obtained and RT-PCR was performed for the identification of TLR4. Secretion of TNFalpha by these cells was evaluated by ELISA of the supernatant.

Results: Limbal epithelial cells expanded in vitro constitutively expressed the TLR4 molecule. After stimulation of cells with LPS the average fluorescence intensity increased, indicating that the expression of extracellular TLR4 was augmented. The expression of TLR4 mRNA was also increased with LPS stimulation, with maximum expression
\end{abstract}

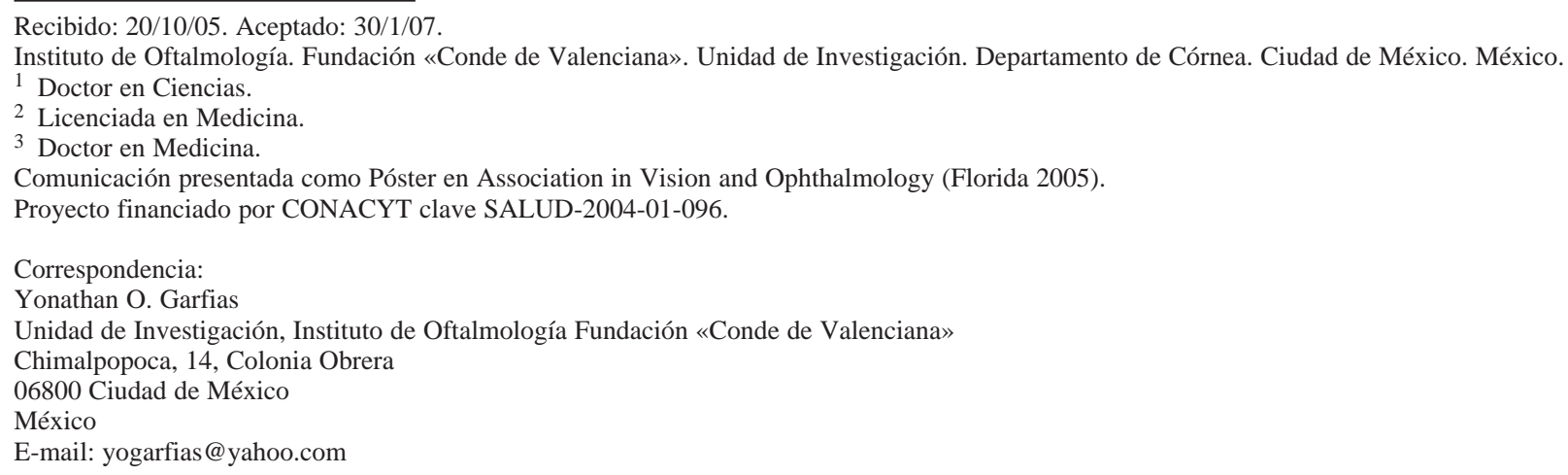


la densidad aumentó, presentando el máximo de expresión con $10 \mathrm{ng} / \mathrm{ml}$ de LPS. Cuando la secreción de TNF-alfa fue evaluada, no se demostró diferencia en la concentración de esta citocina en el sobrenadante de las células estimuladas y las no estimuladas.

Conclusiones: Aunque la expresión extracelular de TLR4 en las células epiteliales limbales estimuladas in vitro regula positivamente al TLR4, su función parece no estar asociada a la secreción de TNF-alfa por el epitelio limbal. Tomando en conjunto estos resultados coinciden con los propuestos que el epitelio corneal favorece que la córnea sea un sitio inmunoprivilegiado.

Palabras clave: Epitelio limbal, TLR4, inmunidad innata, córnea, LPS. measured at $10 \mathrm{ng} / \mathrm{ml}$ LPS. The level of TNF-alpha in the supernatant was not different between the stimulated and the non-stimulated cells.

Conclusions: Although stimulation of in vitro limbal epithelial cells with LPS up-regulates the extracellular expression of TLR4, the function of TLR4 does not seem to be associated with the secretion of TNF-alpha by these cells. These results are consistent with the proposal that the corneal epithelium is an immunosilent site in the eye (Arch Soc Esp Oftalmol 2007; 82: 95-102).

Key words: Limbal epithelium, TLR4, innate immunity, cornea, LPS.

\section{INTRODUCCIÓN}

La manera de iniciar la respuesta inmune en células de la inmunidad innata es a través de la activación de receptores que pertenecen al grupo de los Toll Like Receptors (TLR). En mamíferos se han identificado 11 miembros de la familia de TLR, estructuralmente caracterizados por secuencias repetidas de leucina en su región extracelular y dominios Toll/IL-1 receptor (TIR) en su región intracelular. Esta región TIR es capaz de transducir señalización al interior de la célula (1). La expresión de los TLR es muy amplia, se han identificado en células relacionadas con la inmunidad innata como las células dendríticas, los monocitos y las células cebadas $(2,3)$; en células del sistema nervioso central (4), así como en mucosa intestinal y epitelios renal y respiratorio (5-7). En el epitelio corneal se han identificado TLR4 y TLR5 $(8,9)$; receptores que están participando en el mecanismo de inmunopatogenia de infecciones por filaria y $\mathrm{Pseu}$ domonas, respectivamente. Los TLR tienen como ligandos a patrones moleculares asociados a patógenos (PAMP); los PAMP que se expresan conservados entre especies de microorganismos, son componentes de la pared bacteriana como lipopolisacárido (LPS), ácido teicoico y lipoteicoico, flagelina; estructuras genómicas bacterianas y virales como CpG no metilados; componentes virales como RNA de doble cadena entre una lista muy variada de componentes $(10,11)$. Aunque se ha demostrado la existencia de los TLR en células epiteliales corneales su función es controversial. Algunos autores afirman que su presencia en el epitelio corneal es fundamental para mantener una respuesta inmune adecuada, sin embargo otros autores mencionan que aunque su existencia se ha comprobado en el epitelio corneal, no se relacionan con una inmunidad activa colaborando así en el privilegio inmunológico. El objetivo del presente trabajo fue determinar si existe la expresión de TLR4 en superficie del epitelio corneal a nivel del limbo y si la expresión de esta molécula es funcional.

\section{SUJETOS, MATERIAL Y MÉTODOS}

\section{Obtención de células epiteliales limbales (CEL)}

Se obtuvieron las células epiteliales del limbo de rodetes esclero-corneales posterior a un transplante de córnea. La inserción del iris y descemet fueron disecados, el rodete se incubó con 1,2 UI de dispasa II (Roche, Mannheim, Alemania) durante $15 \mathrm{~min}$ a $37^{\circ} \mathrm{C}$, las células epiteliales fueron separadas de las estromales mediante una malla de nylon y recolectadas en una caja de Petri. Se lavaron con medio DMEM (Modified Eagle Medium) (Gibco, Grand Island, NY, USA) y se determinó su pureza por citometría de flujo. Las células se expandieron en presencia de medio epidermal hormonal suplementado (SHEM) en cajas de 24 pozos (Costar, NY, USA). 
El SHEM consiste en DMEM/F12 v/v (Gibco, Grand Isalnd, NY, USA), factor de crecimiento epidermal (Sigma, St. Louis Missouri, USA), insulina, tranferrina, selenio (Roche, Mannheim, Alemania), hidrocortisona, gentamicina, estreptomicina, penicilina, anfotericina B (Sigma, St. Louis Missouri, USA), $10 \%$ de suero fetal bovino (Gibco, Grand Island, NY, USA). Cuando las células alcanzaron un $80 \%$ de confluencia, se utilizó tripsina (Gibco, Grand Island, NY, USA) para despegarlas de la superficie y se pasaron a una caja de $25 \mathrm{~mm}^{2}$ (Costar, NY, USA). Se cultivaron 17-20 días adicionales hasta que alcanzaron una confluencia del 90\%, y fue al primero y segundo pases cuando se utilizaron para los ensayos posteriores.

\section{Obtención de células mononucleadas (CMN)}

Las CMN se obtuvieron por el método de gradiente de Ficoll. Se cuantificó el número de células y se valoró la viabilidad por medio del método de exclusión de azul tripan.

\section{Ensayos de estimulación con lipopolisacárido (LPS)}

Una vez expandidas las CEL y obenidas las CMN, se adicionó al medio SHEM y RPMI (Sigma, St. Louis Missouri, USA) respectivamente, diferentes dosis de LPS de E. Coli y P. aeruginosa (Sigma, St. Louis Missouri, USA) a 24 y 48 h. El sobrenadante se colectó y se preservó a $-70^{\circ} \mathrm{C}$ para determinar citocinas.

\section{Determinación de citocinas en sobrenadante}

Los sobrenadantes se descongelaron a temperatura ambiente (TA) y se centrifugaron a $12.000 \mathrm{rpm}$ durante $5 \mathrm{~min}$, se recolectó el sobrenadante. Se realizaron los ensayos de ELISA según la metodología propuesta por el fabricante (R\&D Systems, Minneapolis, MN, USA). Los anticuerpos de captura se unieron a una placa Immunosorp (Nunc, Dinamarca) a TA durante toda la noche. Se retiraron los anticuerpos de captura y se lavó la placa tres veces con amortiguador de lavado (buffer de fosfatos ph 7.2, $0,05 \%$ de Tween); se adicionaron las muestras problema así como el estándar de la citocina recombi- nante humana a determinar (TNF-alfa), la placa se dejó incubando durante 2 h a TA, se retiró el sobrenadante y se lavó tres veces con amortiguador de lavado; se adicionaron los anticuerpos de detección conjugados a biotina durante $1 \mathrm{~h}$ a TA, la placa se lavó tres veces con amortiguador de lavado, se retiró el sobrenadante y se agregó estreptavidina conjugada a peroxidasa, la placa se dejó incubando 45 min a TA, se lavó tres veces con amortiguador de lavado, se agregó el substrato más el cromógeno (peróxido de hidrógeno y 3,3'5,5' tetrametil diaminobenzidina), se detuvo la reacción con ácido sulfúrico $2 \mathrm{~N}$. Se leyó a $450 \mathrm{~nm}$ de absorbancia en un lector de ELISA (Thermolabsystems, Helsinki, Finlandia). Se calculó la concentración con respecto a una regresión lineal del estándar de la citocina recombinante.

\section{Determinación de mRNA de TLR4}

Después de la estimulación con LPS, el RNA total de la CEL se obtuvo por medio de un kit de extracción de RNA (Qiagen Sciences, Maryland, USA) según la metodología sugerida por el fabricante. Las células se incubaron durante 1 min con amortiguador de lisis, etanol al 70\%, se utilizaron columnas de purificación, se centrífugo la mezcla a 10.000 rpm durante $15 \mathrm{seg}$, se lavó con amortiguador de lavado a $10.000 \mathrm{rpm}$ durante $15 \mathrm{seg}$, se utilizó agua libre de endonucleasas para eluir el RNA total. Posteriormente se realizó la retrotranscripción utilizando transcriptasa reversa (Qiagen Sciences, Maryland, USA) y como primer oligo-dT (Invitrogen, Carlsbad, CA, USA). Se dejó incubando la reacción durante $1 \mathrm{~h}$ a $37^{\circ} \mathrm{C}$. Se realizó la reacción en cadena de la polimerasa utilizando como sustrato el DNA complementario que resultó de la retrotranscripción. Las condiciones del PCR fueron: para TLR4 [forward, - CTG CAA TGG ATC AAG GAC CA-; reverse, - TCC CAC TCC AGG TAA GTG TT—; $95^{\circ} \mathrm{C} 15$ min, 35 ciclos $\left(94^{\circ} \mathrm{C} 30 \mathrm{seg}, 62^{\circ} \mathrm{C} 30 \mathrm{seg}, 72^{\circ} \mathrm{C} 30 \mathrm{seg}\right), 72^{\circ} \mathrm{C}$ $10 \mathrm{~min}$ ]. Y para GADPH [forward, - CAT TGT GGA AGG GCT CAT GA-; reverse, —GGA AGG CCA TGC CAG TGA GC-; $95^{\circ} \mathrm{C} 15 \mathrm{~min} ; 25$ ciclos $\left(94^{\circ} \mathrm{C} 50 \mathrm{seg}, 55^{\circ} \mathrm{C} 50 \mathrm{seg}, 72^{\circ} \mathrm{C} 50 \mathrm{seg}\right), 72^{\circ} 10$ min]. Se utilizó para la reacción un termociclador 9400 (Applied Biosystems, Foster City, CA, USA).

Los productos de las reacciones se analizaron en un gel de agarosa al 1,5\%. Se documentó mediante un transiluminador con luz UV. Se realizó densito- 
metría a los productos mediante el software Kodak $1 \mathrm{D}$, utilizando el producto de GADPH como gen constitutivo.

\section{Determinación de TLR4 extramembranal}

Después de la estimulación con LPS a diferentes concentraciones, las CEL se cosecharon y se lavaron dos veces con buffer de lavado (amortiguador de fosfatos $\mathrm{pH} 7,2$, albúmina sérica bovina $0,2 \%$, azida de sodio $0,2 \%$ ), se incubaron 15 min a TA con anticuerpos murinos contra TLR4 humano (Ebioscience, San Diego, CA, USA) conjugados a ficoeritrina; posteriormente las CEL se lavaron una vez con amortiguador de lavado y se analizaron por citometría de flujo.

\section{Análisis estadístico}

Se realizó la comparación de datos de grupos independientes utilizando la «t» de Student y se consideró una $\mathrm{p}<0,05$ como estadísticamente significativa. Los análisis se realizaron en el programa SigmaStat 2.0.

\section{RESULTADOS}

\section{Obtención de CEL}

Después de ser tratados los rodetes esclero-corneales con dispasa II, se analizó la frecuencia de las células epiteliales limbales tomando en cuenta el porcentaje de células positivas a citoqueratina, obteniendo $>70 \%$ de células (fig. 1a). Al realizar los ensayos de expansión in vitro, se observó que estas células continuaban teniendo un fenotipo epitelial, observándolas al microscopio invertido (fig. 1b) y por citometría de flujo, donde se observa que siguen manteniendo una frecuencia similar a la frecuencia que se presenta en las células epiteliales recién obtenidas, sin embargo aunque la densidad de expresión de la citoqueratina por cada célula es menor (fig. 1c).

\section{Expresión de TLR4}

Las CEL posterior al primer y segundo pases, además de conservar su fenotipo epitelial también

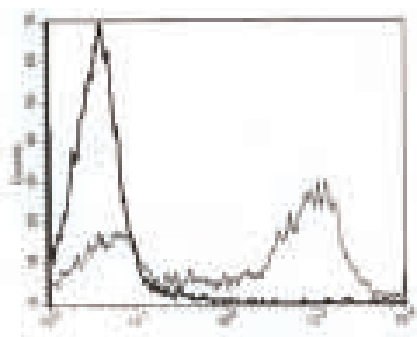

A

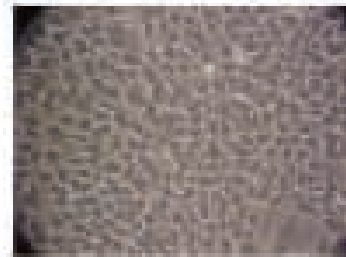

B

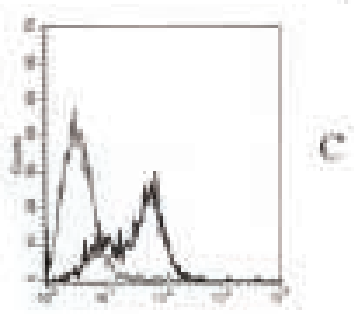

Fig. 1: Células epiteliales limbales. A) Histograma de un ensayo de citometría de flujo donde se observa en línea más gruesa células incubadas con el control de isotipo y en línea más delgada las células marcadas con anti-citoqueratina conjugada a fluoresceina; B) Microfotografía en contraste de fases de células epiteliales limbales cultivadas in vitro posterior al primer pase; C) Las células epiteliales limbales fueron cultivadas por 20 días y después de dos pases fueron incubadas con anticuerpos contra citioqueratina conjugados a fluoresceína (línea gruesa), otra muestra de células se utilizó como control de isotipo (línea delgada). Son muestras representativas de al menos tres ensayos con resultados similares.

expresaron aunque de baja densidad la molécula TLR4 constitutivamente, sin embargo posterior a la estimulación con LPS, la expresión de esta molécula se incrementó, tomando en cuenta la intensidad media de fluorescencia (fig. 2).

\section{Expresión del mRNA de TLR4 en CEL}

Posterior a la expansión in vitro de estas células, se observó la presencia constitutiva de mRNA de TLR4, asimismo su expresión fue inversamente proporcional a la dosis de LPS, expresando mayor mRNA de TLR4 con un estímulo de $10 \mathrm{ng} / \mathrm{ml}$ de LPS y disminuyendo conforme se aumentaba la dosis, obteniendo una expresión menor a $100 \mathrm{ng} / \mathrm{ml}$ y aún menor a $1.000 \mathrm{ng} / \mathrm{ml}$ de LPS (fig. 3); las diferencias que se observaron fueron estadísticamente significativas entre la densidad de expresión del amplificado de las CEL sin estímulo con respecto a 


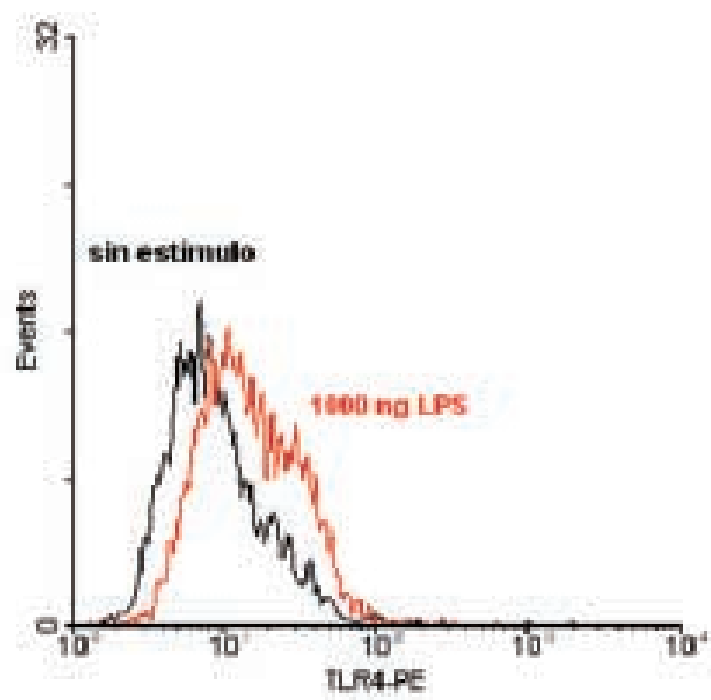

Fig. 2: Expresión de TLR4 en CEL. Después del primer o segundo pases, las células fueron cosechadas y marcadas con anticuerpos anti-TLR4 conjugados a ficoeritrina, las células se analizaron mediante citometría de flujo. Histograma donde se observa en línea negra las células epiteliales limbales sin estímulo y en línea roja las células epiteliales limbales cultivadas con LPS durante 24 h. Es muestra de al menos tres ensayos representativos.

la densidad de expresión del amplificado a dosis de 10 y $100 \mathrm{ng} / \mathrm{ml}(\mathrm{p}<0,05)$.

\section{Determinación de TNF-alfa en sobrenadante de las cultivadas in vitro}

Posterior a la estimulación con LPS, se determinó la secreción de TNFalfa de las CEL mediante ELISA. No se observaron diferencias entre las células estimuladas y las células no estimuladas, aún a altas dosis como $1.000 \mathrm{ng} / \mathrm{ml}$, ni con LPS de E. Coli, ni con LPS de Pseudomonas (fig. 4), e incluso posterior a $48 \mathrm{~h}$ de estímulo (resultados no mostrados). Para determinar que el sistema de activación y secreción de TNF-alfa mediante la estimulación de LPS, se incubaron CMN con las mismas concentraciones de LPS durante los mismos períodos de tiempo, en este ensayo se determinó que existe una dosis respuesta de LPS, se observó que hay una secreción de TNF-alfa dosis dependiente. Lo que indica que se conserva el sistema de activación mediante LPS (fig. 5).

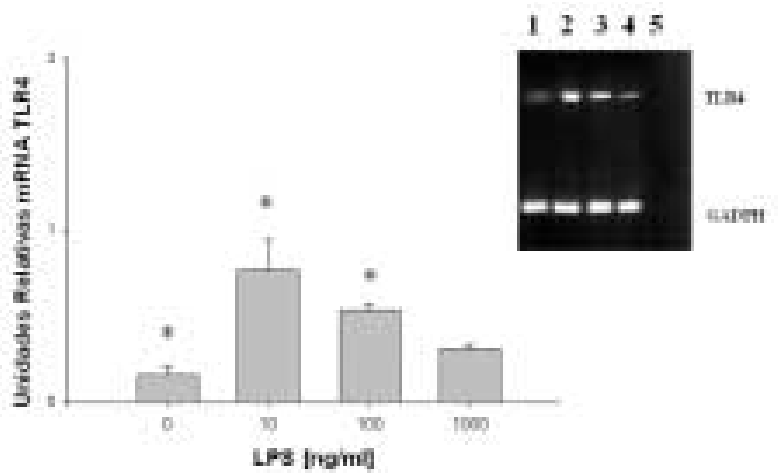

Fig. 3: Efecto de LPS sobre la expresión de mRNA de TLR4. Las células epiteliales limbales se expandieron in vitro y al primero o segundo pases fueron cultivadas a diferentes concentraciones de LPS de E.coli (0-1000 $n g / m l)$ durante $24 \mathrm{~h}$. Se realizó PCR con el cDNA obtenido de la retrotranscripción del RNA total obtenido de las CEL. De lado superior derecho se observa la fotografía de un gel de agarosa al 1,5\% teñido con bromuro de etidio; en el carril 1 no hay estimulación, carriles 2,3 y 4: 10, 100 y $1.000 \mathrm{ng} / \mathrm{ml}$ de LPS respectivamente; carril 5 es el control de las reacciones tanto de TLR4 como de GADPH sin cDNA, resultados de tres ensayos similares. Se realizó densitometría y se obtuvieron los datos para la gráfica. $n=3\left(*^{*}<<0,05\right)$.

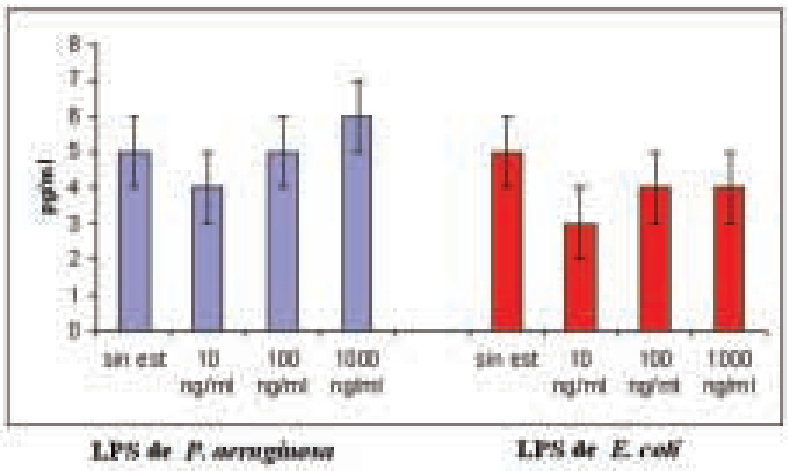

Fig. 4: Determinación de TNF-alfa en sobrenadante de CEL. El sobrenadante de las células epiteliales limbales se colectó 24 h posterior al estímulo con diferentes dosis de LPS de Pseudomonas y de E. Coli. Se realizó determinación de TNF-alfa mediante ELISA. Se representa del lado izquierdo de la gráfica en barras azules la estimulación con LPS de Pseudomonas y del lado derecho de la gráfica en barras rojas la estimulación con LPS de E.coli. $n=3( \pm E S)$. 


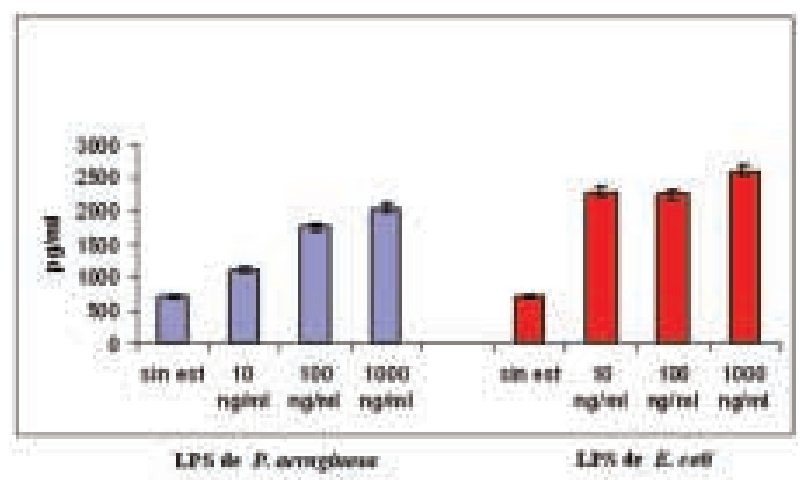

Fig. 5: Determinación de TNF-alfa en sobrenadante de CMN. El sobrenadante de las CMN se colectó posterior al estímulo de LPS de Pseudomonas y de E.coli. Se realizó determinación de TNF-alfa mediante ELISA. Se representa del lado izquierdo de la gráfica en barras azules la estimulación con LPS de Pseudomonas y del lado derecho de la gráfica en barras rojas la estimulación con LPS de E.coli. $n=3( \pm E S)$.

\section{DISCUSIÓN}

La identificación en células de la superficie ocular y la función de receptores de la inmunidad innata como los TLR ha sido controversial. En el presente trabajo se ha determinado que en células epiteliales del limbo esclero-corneal expandidas in vitro, se expresa constitutivamente el TLR4 y que su regulación positiva no favorece la secreción de TNF-alfa. Se ha descrito que la expresión intracelular de TLR2 y TLR4 no es capaz de transducir señales al interior de la célula epitelial corneal (12), estos resultados indican que la ausencia en la señalización por parte de estas moléculas favorecen a la córnea como un sitio inmunosilente, en este trabajo se observa que posterior a la activación celular con LPS, aún a dosis elevadas, de igual manera no hay secreción de TNF-alfa; sin embargo, se alcanza a observar que sí existe activación celular debido a que hay un aumento en la expresión de la molécula TLR4, desde el mRNA como la proteína extramembranal. Se puede observar que el sistema de secreción de TNF-alfa así como la identificación de esta citocina mediante ELISA fueron adecuados como se demuestra en el ensayo de activación con LPS en CMN, donde se observa que hay una elevación de esta citocina de una manera dosis respuesta, lo que confirma que durante la activación de las células epiteliales limbales con LPS no hay una respuesta adecuada al LPS en cuanto a la secreción de
TNF-alfa, esto puede conducir a un estado de inmunomodulación localizada que contribuye entonces a que la córnea sea un sitio inmunoprivilegiado. Por otro lado, en un modelo murino se ha determinado la función del TLR4 donde se demuestra que a través de la estimulación con LPS hay una activación de MyD88, una proteína adaptadora que contribuye en la translocación nuclear del factor de transcripción NFkappaB, lo que indica que el TLR4 es capaz de activar genes de proteínas proinflamatorias (13), sugiriendo así una participación en la respuesta inmune de esta molécula. En contraste con estos resultados existen ensayos donde se demuestra que en el caso de la Wolbachia, la vía de entrada del patógeno es a través de las células epiteliales mediada ésta por TLR4 (8), además se han realizado experimentos con LPS de Pseudomonas (50 ng/ml) en células epiteliales limbales donde se observa que responden con movimiento de calcio intracelular y sobreexpresión de TLR4 (14), estos hallazgos apoyan los encontrados en el presente trabajo, donde se observa una activación celular en cuanto a la expresión de TLR4, si esta participación esta mediando una respuesta midiendo otras citocinas proinflamatoias o reguladoras, está por determinarse.

En conclusión, nuestros hallazgos indican que las células del epitelio limbal son capaces de reconocer y activarse mediante LPS, sin embargo no hay evidencia que muestre que esta activación favorezca la respuesta inmune proinflamatoria, esto podría traer como favorecer el inmunoprivilegio observado en córnea.

\section{BIBLIOGRAFÍA}

1. Muzio M, Ni J, Feng P, Dixit VM. IRAK (Pelle) family member IRAK-2 and MyD88 as proximal mediators of IL1 signaling. Science 1997; 278: 1612-1615.

2. Visintin A, Mazzoni A, Spitzer JH, Wyllie DH, Dower SK, Segal DM. Regulation of Toll-like receptors in human monocytes and dendritic cells. J Immunol 2001; 166: 249255.

3. Supajatura V, Ushio H, Nakao A, Akira S, Okumura K, Ra $C$, et al. Differential responses of mast cell Toll-like receptors 2 and 4 in allergy and innate immunity. J Clin Invest 2002; 109: 1351-1359.

4. Bottcher T, von Mering M, Ebert S, Meyding-Lamade, Kuhnt U, Gerber J, et al. Differential regulation of Tolllike receptor $m R N A s$ in experimental murine central nervous system infections. Neurosci Lett 2003; 344: 17-20.

5. Hornef $M W$, Frisan T, Vandewalle A, Normark S, RichterDahlfors A. Toll-like receptor 4 resides in the Golgi apa- 
ratus and colocalizes with internalized lipopolysaccharide in intestinal epithelial cells. J Exp Med 2002; 195: 559570 .

6. Wang X, Moser C, Louboutin JP, Lysenko ES, Weiner DJ, Weiser JN, et al. Toll-like receptor 4 mediates innate immune responses to Haemophilus influenzae infection in mouse lung. J Immunol 2002; 168: 810-815.

7. Wolfs TG, Buurman WA, van Schadewijk A, de Vries B, Daemen MA, Hiemstra PS, et al. In vivo expression of Toll-like receptor 2 and 4 by renal epithelial cells: IFNgamma and TNF-alpha mediated up-regulation during inflammation. J Immunol 2002; 168: 1286-1293.

8. Saint Andre A, Blackwell NM, Hall LR, Hoerauf A, Brattig NW, Volkmann L, et al. The role of endosymbiotic Wolbachia bacteria in the pathogenesis of river blindness. Science 2002; 295: 1892-1895.

9. Zhang J, Xu K, Ambati B, Yu FS. Toll-like receptor 5mediated corneal epithelial inflammatory responses to Pseudomonas aeruginosa flagellin. Invest Ophtalmol Vis Sci 2003; 44: 4247-4254.
10. Lund J, Sato A, Akira S, Medzhitov R, Iwasaki A. Toll-like receptor 9-mediated recognition of Herpes simplex virus2 by plasmacytoid dendritic cells. J Exp Med 2003; 198: 513-520.

11. Takeda K, Kaisho T, Akira S. Toll-like receptors. Ann Rev Immunol 2003; 21: 335-376.

12. Ueta $M$, Nochi $T$, Jang $M H$, Park EJ, Igarashi $O$, Hino A, et al. Intracellularly expressed TLR2s and TLR4s contribution to an immunosilent environment at the ocular mucosal epithelium. J Immunol 2004; 173: 3337-3347.

13. Jonson AC, Heinzel FP, Diaconu E, Sun Y, Hise AG, Golenbock D, et al. Activation of toll-like receptor (TLR)2, TLR4, and TLR9 in the mammalian cornea induces MyD88-dependent corneal inflammation. Invest Ophthalmol Vis Sci 2005; 46: 589-595.

14. Song PI, Abraham TA, Park Y, Zivony AS, Harten B, Edelhauser HF, et al. The expression of functional LPS receptor proteins CD14 and toll-like receptor 4 in human corneal cells. Invest Ophthalmol Vis Sci 2001; 42: 28672877. 